Pacific Journal of Mathematics

ON THE FROBENIUS RECIPROCITY THEOREM FOR
SQUARE-INTEGRABLE REPRESENTATIONS 


\title{
ON THE FROBENIUS RECIPROCITY THEOREM FOR SQUARE-INTEGRABLE REPRESENTATIONS
}

\author{
RAY A. KUNZE
}

\begin{abstract}
In this paper, a global version of the Frobenius reciprocity theorem is established for irreducible square-integrable representations of locally compact unimodular groups. As in the classical compact case, it asserts that certain intertwining spaces are canonically and isometrically isomorphic. The proof is elementary, and the appropriate isomorphism is exhibited explicitely. The essential point is that squareintegrability implies the continuity of functions in certain subspaces of $L^{2}$ spaces on which the group acts and leads to a characterization of the subspaces in terms of reproducing kernels.
\end{abstract}

The preliminary results on reproducing kernels are contained in Theorems 1 and 2 in $\S 2$. Our main result on reciprocity, Theorem 3 in $\S 3$, does not require direct integral decomposition theory as in [2] and [4] and is formally similar to the version of the reciprocity theorem proved by C. C. Moore in [5]; however, we only consider unitary representations, and do not need to formulate the result in terms of summable induced representations on $L^{1}$-spaces.

After this paper was initially submitted, we learned that A. Wawrzyńczyk [6] had already proved a result, similar but not identical to our Theorem 3. His proof is based on a general duality theorem for automorphic forms due to K. and L. Maurin [3], and he does not prove results corresponding to our Theorems 1 and 2 .

Let $G$ be a locally compact unimodular group and $S$ a continuous irreducible square-integrable unitary representation of $G$ on a complex Hilbert space $\mathscr{H}$. We recall that this implies

$$
x \rightarrow(S(x) \varphi \mid \psi), x \in G
$$

is square-integrable on $G$ for all $\varphi$ and $\psi$ in $\mathscr{H}$ and the existence of a positive constant $d$ (the formal degree) such that

$$
\int_{G}(S(x) \varphi \mid \alpha) \overline{(S(x) \psi \mid \beta)} d x=d^{-1}(\varphi \mid \psi) \overline{(\alpha \mid \beta)}
$$

for all $\varphi, \alpha, \psi, \beta$ in $\mathscr{H}$.

Let $K$ be a compact subgroup of $G$ and $\lambda$ a continuous irreducible unitary representation of $K$ on a complex-Hilbert space $\mathscr{K}$. Let $T=T(\cdot, \lambda)$ be the continuous unitary representation of $G$ induced by $\lambda$. By definition, $T(y)(y \in G)$ is right translation by $y$ on the space $L^{2}(G, \lambda)$ of all square-integrable maps $f: G \rightarrow \mathscr{K}$ such that 


$$
f(k x)=\lambda(k) f(x)
$$

for all $(k, x)$ in $K \times G$.

Now let $\mathscr{F}(S, T)$ denote the Banach space of bounded linear maps $U: \mathscr{H} \rightarrow L^{2}(G, \lambda)$ which intertwine $S$ and $T$, i.e., are such that

$$
U S(x)=T(x) U
$$

for all $x$ in $G$. Similarly, let $\mathscr{F}\left(S_{K}, \lambda\right)$ denote the space of operators intertwining $S_{K}$ (the restriction of $S$ to $K$ ) and $\lambda$.

In $\S 2$, we obtain certain properties of the spaces $U(\mathscr{H})$ for $U$ in $\mathscr{F}(S, T)$, and using these properties, we then show in $\S 3$ that there is a canonical isometric isomorphism of $\mathscr{I}\left(S_{K}, \lambda\right)$ onto $\mathscr{J}(S, T)$. From this we conclude that $T$ contains $S$ (discretely) exactly as many times as $S_{K}$ contains $\lambda$.

2. The spaces $U(\mathscr{H}), U \in \mathscr{I}(S, T)$. Because $S$ is irreducible, it is easy to see that each $U$ in $\mathscr{F}(S, T)$ is a scalar multiple of an isometry (cf. the argument proving (3.3)). Hence, $U(\mathscr{H})$ is a closed subspace (possibly 0 ) of $L^{2}(G, \lambda)$. Less obvious and much more important is the fact that each function class $U \varphi(U \in \mathscr{I}(S, T), \varphi \in \mathscr{H})$ contains a unique continuous function.

THEOREM 1. Let $U$ be any operator intertwining $S$ and $T$. Then $U(\mathscr{H})$ is a closed subspace of $L^{2}(G, \lambda)$ consisting of continuous functions in which point evaluations

$$
f \rightarrow f(x), \quad f \in U(\mathscr{C})
$$

are continuous linear maps of $U(\mathscr{H})$ into $\mathscr{K}$ for every $x$ in $G$.

Proof. Let $\varphi \in \mathscr{C}$ and $f$ any function in the class $U \varphi$. Set

$$
e(y)=d(\varphi \mid S(y) \varphi), \quad y \in G \text {. }
$$

Then, because $G$ is unimodular and in view of (1.1), it follows that

$$
\begin{aligned}
& \int_{G}|e(y)|\|f(x y)\| d y \leqq\left(\int_{G}|e(y)|^{2} d y\right)^{1 / 2}\left(\int_{G}\|f(x y)\|^{2} d y\right)^{1 / 2} \\
= & d^{1 / 2}\|\varphi\|^{2}\|f\|_{2} .
\end{aligned}
$$

Thus, we can define a bounded function $g: G \rightarrow \mathscr{K}$ which satisfies (1.2) by setting

$$
g(x)=\int_{G} e(y) f(x y) d y .
$$

Moreover, $g$ is continuous. For 


$$
\begin{aligned}
\|g(x)-g(z x)\| & \leqq \int_{G} \mid e(y)\|\| f(x y)-f(z x y) \| d y \\
& \leqq d^{1 / 2}\|\varphi\|^{2}\left(\int_{G}\|f(y)-f(z y)\|^{2} d y\right)^{1 / 2} \rightarrow 0 \text { as } \quad z \rightarrow 1
\end{aligned}
$$

Now let $h$ be any function with compact support in $L^{2}(G, \lambda)$. Then

$$
\begin{aligned}
& \int_{G}(g(x) \mid h(x)) d x \\
= & \int_{G}\left(\int_{G} e(y) f(x y) d y \mid h(x)\right) d x=\int_{G} d x \int_{G} e(y)(f(x y) \mid h(x)) d y \\
= & \int_{G} d y \int_{G} e(y)(f(x y) \mid h(x)) d x=\int_{G} e(y)(T(y) f \mid h) d y \\
= & \int_{G} e(y)(U S(y) \varphi \mid h) d y \\
= & d \int_{G}\left(S(y) \varphi \mid U^{*} h\right) \overline{(S(y) \varphi \mid \varphi)} d y \\
= & \left(\varphi \mid \varphi \overline{\left(U^{*} h \mid \varphi\right)}\right. \\
= & \left(\|\varphi\|^{2} f \mid h\right) .
\end{aligned}
$$

Since this holds for all such $h$, it follows that

$$
g(x)=\|\varphi\|^{2} f(x), \text { a.e. . }
$$

Because the complement of a set of Haar measure 0 is dense, it follows that each function class $U \varphi$ contains a unique continuous function; from now on that function will be denoted by $U \varphi$.

Suppose $\phi \neq 0$. Then from (2.1), (2.2) and the computations above, we have

$$
(U \varphi)(x)=\frac{d}{\|\varphi\|^{2}} \int_{G}(U \varphi)(x y) \overline{(S(y) \varphi \mid \varphi)} d y
$$

and

$$
\|U \varphi(x)\| \leqq d^{1 / 2}\|U \varphi\|_{2}
$$

for every $x$ in $G$. Therefore, point evaluations are continuous.

Now suppose $U(\mathscr{H}) \neq 0$. Then, since the maps

$$
E_{x}: f \rightarrow f(x), \quad f \in U(\mathscr{H}), \quad x \in G
$$

are all continuous, $U(\mathscr{H})$ is completely determined by the positive definite kernel

$$
Q(x, y)=E_{x} E_{y}^{*}
$$

in the simple fashion described in [1]. On the other hand, it is easy to see directly that $Q(x, y)=P\left(x y^{-1}\right)$ where 


$$
P(x)=E_{1} T(x) E_{1}^{*}, \quad x \in G
$$

and that following result is valid.

THEOREM 2. The operator-valued function $P$ is continuous and square-integrable on $G$. It has formal properties

(1) $P(x)^{*}=P\left(x^{-1}\right)$

(2) $P\left(x y^{-1}\right)=E_{x} E_{y}^{*}$

(3) $P\left(k_{1} x k_{2}\right)=\lambda\left(k_{1}\right) P(x) \lambda\left(k_{2}\right)$

(4) $P(x)=\int_{G} P\left(x y^{-1}\right) P(y) d y$

which are valid for all $k_{1}, k_{2}$ in $K$ and $x, y$ in $G$. Moreover, left convolution by $P$ is the orthogonal projection of $L^{2}(G, \lambda)$ on $U(\mathscr{H})$; in particular.

$$
\text { (5) } f(x)=\int_{G} P\left(x y^{-1}\right) f(y) d y
$$

for all $f$ in $U(\mathscr{H})$ and $x$ in $G$.

Proof. Equation (1) follows from (2.6); (2) and (3) are consequences of the relations $E_{x}=E_{1} T(x)(x \in G)$ and $E_{1} T(k)=\lambda(k) E_{1}(k \in K)$. If $\alpha$ and $\beta$ are vectors in $\mathscr{\kappa}$, then

$$
(P(\curvearrowright) \alpha \mid \beta)=\left(T(x) E_{1}^{*} \alpha \mid E_{1}^{*} \beta\right)
$$

and since $T$ is equivalent to $S$ in $U(\mathscr{H})$, it follows that $x \rightarrow(P(x) \alpha \mid \beta)$ is not only continuous but square-integrable on $G$. We also have

$$
\begin{aligned}
(P(x) \alpha \mid \beta) & =\left(E_{1}^{*} \alpha \mid T\left(x^{-1}\right) E_{1}^{*} \beta\right) \\
& =\int_{G}\left(E_{1}^{*} \alpha(y) \mid T\left(x^{-1}\right) E_{1}^{*} \beta(y)\right) d y \\
& =\int_{G}\left(E_{y} E_{1}^{*} \alpha \mid E_{y} T\left(x^{-1}\right) E_{1}^{*} \beta\right) d y \\
& =\int_{G}\left(P(y) \alpha \mid P\left(y x^{-1}\right) \beta\right) d y \\
& =\int_{G}\left(P\left(x y^{-1}\right) P(y) \alpha \mid \beta\right) d y
\end{aligned}
$$

for all $\alpha, \beta$ in $\mathscr{K}$; hence, (4) is true.

Now suppose $f \in L^{2}(G, \lambda)$. Then for any $x$ in $G$ and $\alpha$ in $\mathscr{Y}$

$$
\begin{aligned}
\left(f \mid T\left(x^{-1}\right) E_{1}^{*} \alpha\right) & =\int_{G}\left(f(y) \mid\left(T\left(x^{-1}\right) E_{1}^{*} \alpha\right)(y)\right) d y \\
& =\int_{G}\left(f(y) \mid E_{y} T\left(x^{-1}\right) E_{1}^{*} \alpha\right) d y \\
& =\int_{G}\left(f(y) \mid P\left(y x^{-1}\right) \alpha^{\prime}\right) d y=\int_{G}\left(P\left(x y^{-1}\right) f(y) \mid \alpha\right) d y .
\end{aligned}
$$


If $f$ is orthogonal to $U(\mathscr{H})$, then $\left(f \mid T\left(x^{-1}\right) E_{1}^{*} \alpha\right)=0$ for all $x$ and $\alpha$; hence

$$
\int_{G}\left(P\left(x y^{-1}\right) f(y) \mid \alpha\right) d y=0
$$

for all $x$ and $\alpha$. Therefore

$$
\int_{G} P\left(x y^{-1}\right) f(y) d y=0, \quad f \in U(\mathscr{C})^{\perp} .
$$

On the other hand, if $f \in U(\mathscr{H})$, then

$$
\left(f \mid T\left(x^{-1}\right) E_{1}^{*} \alpha\right)=\left(E_{1} T(x) f \mid \alpha\right)
$$

so that

$$
(f(x) \mid \alpha)=\int_{G}\left(P\left(x y^{-1}\right) f(y) \mid \alpha\right) d y
$$

for all $x$ and $\alpha$; hence, (5) is valid. To complete the proof it is enough to observe that (5) and (2.7) imply that for any $f$ in $L^{2}(G, \lambda)$, the function

$$
g(x)=\int_{G} P\left(x y^{-1}\right) f(y) d y, \quad x \in G
$$

is the orthogonal projection of $f$ on $U(\mathscr{H})$.

3. The reciprocity theorem. In the statement of the next result, which is our version of the Frobenius reciprocity theorem for square-integrable representations, we retain the assumptions and notation used in $\S \S 1$ and 2 .

THEOREM 3. The intertwining spaces $\mathscr{F}\left(S_{K}, \lambda\right)$ and $\mathscr{I}(S, T)$ are canonically isomorphic via an isometric linear map

$$
A \rightarrow U_{A}, \quad A \in \mathscr{I}\left(S_{K}, \lambda\right)
$$

that is defined by the equation

$$
\left(U_{A} \varphi\right)(x)=c A S(x) \varphi, \quad \varphi \in \mathscr{L}, \quad x \in G
$$

in which $c=(d / \operatorname{dim}(\mathscr{K}))^{1 / 2}$.

Proof. Let $A \in \mathscr{I}\left(S_{K}, \lambda\right), \varphi \in \mathscr{H}$, and define $f$ on $G$ by

$$
f(x)=A S(x) \varphi, \quad x \in G .
$$

Then $f$ is continuous, and

$$
f(k x)=A S(k) S(x) \varphi=\lambda(k) A S(x) \varphi=\lambda(k) f(x)
$$


for all $(k, x)$ in $K \times G$. If $\alpha \in \mathscr{K}$ then

$$
(f(x) \mid \alpha)=(A S(x) \varphi \mid \alpha)=\left(S(x) \varphi \mid A^{*} \alpha\right) .
$$

Since $S$ is square-integrable, it follows that $x \rightarrow(f(x) \mid \alpha)$ is squareintegrable for each $\alpha$ in $\mathscr{K}$. Hence, since $\mathscr{K}$ is necessarily finite dimensional

$$
\int_{G}\|f(x)\|^{2} d x<\infty \text {. }
$$

It follows that (3.1) defines an element $U_{A} \varphi$ in $L^{2}(G, \lambda)$, and $\varphi \rightarrow U_{A} \varphi(\phi \in \mathscr{H})$ is a linear map $U_{A}$ of $\mathscr{H}$ into $L^{2}(G, \lambda)$.

Now suppose $A$ and $B$ lie in $\mathscr{I}\left(S_{K}, \lambda\right)$, let $\varepsilon_{1}, \cdots, \varepsilon_{n}$ be an orthonormal base for $\mathscr{K}$, and let $\varphi$ and $\psi$ be vectors in $\mathscr{H}$. Then

$$
\left(U_{A} \varphi \mid U_{B} \psi\right)=d^{-1}(\varphi \mid \psi) \sum_{i=1}^{n}\left(B^{*} \varepsilon_{i} \mid A^{*} \varepsilon_{i}\right)
$$

In fact

$$
\begin{aligned}
\int_{G}(A S(x) \varphi \mid B S(x) \psi) d x & =\sum_{i} \int_{G}\left(S(x) \varphi \mid A^{*} \varepsilon_{\imath}\right) \overline{\left(S(x) \psi \mid B^{*} \varepsilon_{i}\right)} d x \\
& =d^{-1}(\varphi \mid \psi) \sum_{i}\left(B^{*} \varepsilon_{i} \mid A^{*} \varepsilon_{i}\right)
\end{aligned}
$$

Because $S$ and $\lambda$ are unitary representations and $A S(k)=\lambda(k) A$, it follows that

$$
A A^{*} \lambda(k)=\lambda(k) A A^{*}
$$

for all $k \in K$. Since $\lambda$ is irreducible this implies $A A^{*}=\|A\|^{2} I$. Hence

$$
\left(A^{*} \alpha \mid A^{*} B\right)=\|A\|^{2}(\alpha \mid \beta)
$$

for all $\alpha, \beta$ in $\mathscr{K}$. Using this and setting $B=A$ in (3.2), we find that

$$
\left(U_{A} \varphi \mid U_{A} \psi\right)=\|A\|^{2}(\varphi \mid \psi)
$$

for all $\varphi, \psi$ in $\mathscr{H}$. Therefore, $U_{A}$ is a continuous linear map of $\mathscr{H}$ into $L^{2}(G, \lambda)$, and $\left\|U_{A}\right\|=\|A\|$.

Next note that for $\varphi$ in $\mathscr{H}$ and $x, y$ in $G$

$$
\left(T(y) U_{A} \varphi\right)(x)=\left(U_{A} \varphi\right)(x y)=c A S(x) S(y) \varphi=\left(U_{A} S(y) \varphi\right)(x) .
$$

Hence, $T(y) U_{A}=U_{A} S(y)$ for all $y$ in $G$. Therefore, $U_{A} \in \mathscr{F}(S, T)$. Since

$$
U_{c A+B}=c U_{A}+U_{B}
$$

it follows that $A \rightarrow U_{A}$ is an isometric linear map of $\mathscr{J}\left(S_{K}, T\right)$ into $\mathscr{J}(S, T)$. 
Now suppose $U \in \mathscr{J}(S, T)$. Then by Theorem 1, we can define a continuous linear map $A$ of $\mathscr{H}$ into $\mathscr{C}$ by setting

$$
A \varphi=c^{-1}(U \varphi)(1), \quad \varphi \in \mathscr{H} \text {. }
$$

Then for $k$ in $K$ and $\varphi$ in $\mathscr{H}$

$$
A S(k) \varphi=c^{-1}(U S(k) \varphi)(1)=c^{-1}(T(k) U \varphi)(1)=c^{-1}(U \varphi)(k)=\lambda(k) A \varphi .
$$

Thus $A \in \mathscr{I}\left(S_{K}, \lambda\right)$, and

$$
U_{A} \varphi(x)=c A S(x) \varphi=(U S(x) \varphi)(1)=(T(x) U \varphi)(1)=(U \varphi)(x)
$$

for $\varphi$ in $\mathscr{H}$ and $x$ in $G$. Hence, $U=U_{A}$ and $A \rightarrow U_{A}\left(A \in \mathscr{J}\left(S_{K}, \lambda\right)\right)$ is an isometric linear map of $\mathscr{J}\left(S_{K}, \lambda\right)$ onto $\mathscr{S}(S, T)$.

COROLlary. The multiplicity of $S$ in $T$ is exactly the same as the multiplicity of $\lambda$ in $S_{K}$.

Proof. These multiplicities are just $\operatorname{dim} \mathscr{J}(S, T)$ and $\operatorname{dim}$ $\mathscr{I}\left(S_{K}, \lambda\right)$, respectively.

\section{REFERENCES}

1. R. A. Kunze, Positive definite operator valued kernels and unitary representations, Proc. of the Conference on Functional Analysis, Irvine, (1966), 235-247.

2. G. W. Mackey, Induced representations of locally compact groups I, Annals of Math., 55 (1952), 101-139.

3. K. Maurin and L. Maurin, A generalization of the duality theorem of Gelfand and Piatecki-Šaprio and Tamagawa automorphic forms, J. Faculty of Sci., University of Tokyo, Sec. I. 17, Part 1 \& 2, 331-340.

4. F. I. Mautner, Induced representations, Amer. J. Math., 74 (1952), 737-758.

5. C. C. Moore, On the Frobenius reciprocity theorem for locally compact groups, Pacific J. Math., 12 (1962), 359-365.

6. A. Wawrzyňczyk, On the Frobenius-Mautner reciprocity theorem, Bulletin De L'Académie Polonaise Des Sciences, 20 (1972), 555-559.

Received May 15, 1973.

University of California, Irvine 



\section{PACIFIC JOURNAL OF MATHEMATICS}

\section{EDITORS}

RICHARD ARENS (Managing Editor)

University of California

Los Angeles, California 90024

\section{J. DUGUNDJI}

Department of Mathematics University of Southern California Los Angeles, California 90007

D. Gilbarg and J. Milgram

Stanford University

Stanford, California 94305

University of Washington
Seattle, Washington 98105

ASSOCIATE EDITORS
E. F, BECKENBACH
B. H. NEUMANN
F. WOLF
K. Yoshida

\section{SUPPORTING INSTITUTIONS}

\author{
UNIVERSITY OF BRITISH COLUMBIA \\ CALIFORNIA INSTITUTE OF TECHNOLOGY \\ UNIVERSITY OF CALIFORNIA \\ MONTANA STATE UNIVERSITY \\ UNIVERSITY OF NEVADA \\ NEW MEXICO STATE UNIVERSITY \\ OREGON STATE UNIVERSITY \\ UNIVERSITY OF OREGON \\ OSAKA UNIVERSITY
}

\author{
UNIVERSITY OF SOUTHERN CALIFORNIA \\ STANFORD UNIVERSITY \\ UNIVERSITY OF TOKYO \\ UNIVERSITY OF UTAH \\ WASHINGTON STATE UNIVERSITY \\ UNIVERSITY OF WASHINGTON \\ * * * * \\ AMERICAN MATHEMATICAL SOCIETY \\ NAVAL WEAPONS CENTER
}

The Supporting Institutions listed above contribute to the cost of publication of this Journal, but they are not owners or publishers and have no responsibility for its content or policies.

Mathematical papers intended for publication in the Pacific Journal of Mathematics should be in typed form or offset-reproduced, (not dittoed), double spaced with large margins. Underline Greek letters in red, German in green, and script in blue. The first paragraph or two must be capable of being used separately as a synopsis of the entire paper. Items of the bibliography should not be cited there unless absolutely necessary, in which case they must be identified by author and Journal, rather than by item number. Manuscripts, in duplicate if possible, may be sent to any one of the four editors. Please classify according to the scheme of Math. Rev. Index to Vol. 39. All other communications to the editors should be addressed to the managing editor, or Elaine Barth, University of California, Los Angeles, California, 90024.

100 reprints are provided free for each article, only if page charges have been substantially paid. Additional copies may be obtained at cost in multiples of 50 .

The Pacific of Journal Mathematics is issued monthly as of January 1966. Regular subscription rate: $\$ 72.00$ a year (6 Vols., 12 issues). Special rate: $\$ 36.00$ a year to individual members of supporting institutions.

Subscriptions, orders for back numbers, and changes of address should be sent to Pacific Journal of Mathematics, 103 Highland Boulevard, Berkeley, California, 94708.

PUBLISHED BY PACIFIC JOURNAL OF MATHEMATICS, A NON-PROFIT CORPORATION

Printed at Kokusai Bunken Insatsusha (International Academic Printing Co., Ltd.), 270, 3-chome Totsuka-cho, Shinjuku-ku, Tokyo 160, Japan.

Copyright (C) 1973 by Pacific Journal of Mathematics Manufactured and first issued in Japan 


\section{Pacific Journal of Mathematics}

\section{Vol. 53, No. $2 \quad$ April, 1974}

Kenneth Abernethy, On characterizing certain classses of first countable spaces by

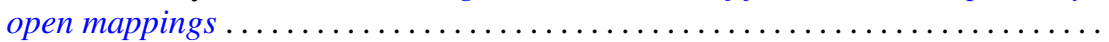

Ross A. Beaumont and Donald Lawver, Strongly semisimple abelian groups .......

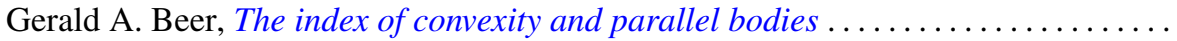

Victor P. Camillo and Kent Ralph Fuller, On Loewy length of rings ..............

Stephen LaVern Campbell, Linear operators for which $T^{*} T$ and $T T^{*}$ commute.

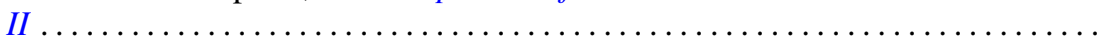

Charles Kam-Tai Chui and Philip Wesley Smith, Characterization of a function by

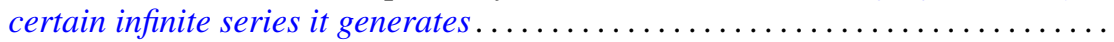

Allan L. Edelson, Conjugations on stably almost complex manifolds . ...........

Patrick John Fleury, Hollow modules and local endomorphism rings . . ..........

Jack Tilden Goodykoontz, Jr., Connectedness im kleinen and local connectedness in

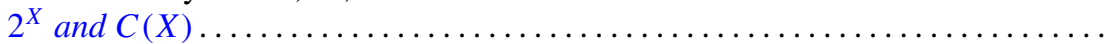

Robert Edward Jamison, II, Functional representation of algebraic intervals .......

Athanassios G. Kartsatos, Nonzero solutions to boundary value problems for

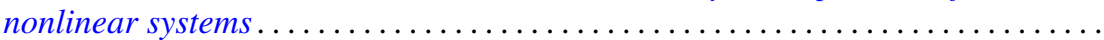

Soon-Kyu Kim, Dennis McGavran and Jingyal Pak, Torus group actions on simply

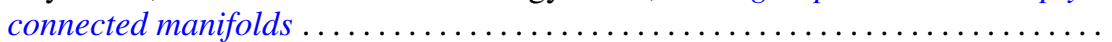

David Anthony Klarner and R. Rado, Arithmetic properties of certain recursively

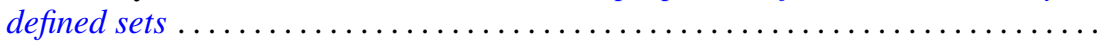

Ray Alden Kunze, On the Frobenius reciprocity theorem for square-integrable

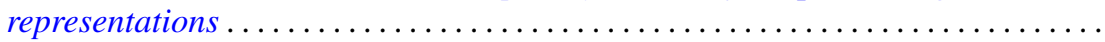

John Lagnese, Existence, uniqueness and limiting behavior of solutions of a class of differential equations in Banach space...

Teck Cheong Lim, A fixed point theorem for families on nonexpansive mappings Lewis Lum, A quasi order characterization of smooth continua

Andy R. Magid, Principal homogeneous spaces and Galois extensions . .

Charles Alan McCarthy, The norm of a certain derivation ..... . .

Louise Elizabeth Moser, On the impossibility of obtaining $S^{2} \times S^{1}$ by elementary surgery along a knot. .

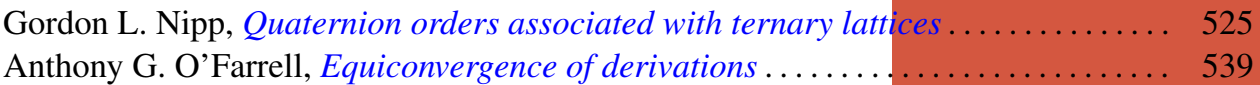

Dorte Olesen, Derivations of $A W^{*}$-algebras are inner . . . . . . . . . . . . . . . 555

Dorte Olesen and Gert Kjærgaard Pedersen, Derivations of $C^{*}$-algebras have

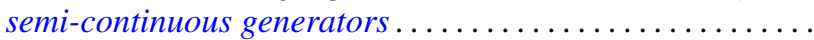

Duane O’Neill, On conjugation cobordism.

Chull Park and S. R. Paranjape, Probabilities of Wiener paths crossing differentiable

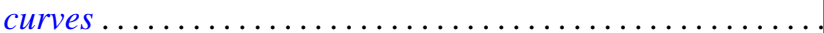

Edward Ralph Rozema, Almost Chebyshev subspaces of $L^{1}(\mu$;

Lesley Millman Sibner and Robert Jules Sibner, A note on the Atiyah-Bott fixed

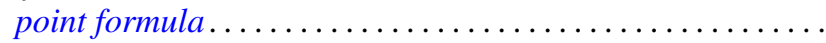

Betty Salzberg Stark, Irreducible subgroups of orthogonal groups generated by

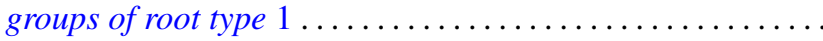

N. Stavrakas, A note on starshaped sets, $(k)$-extreme points and the half ray

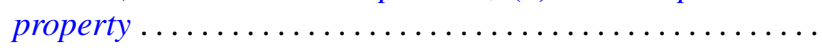

Carl E. Swenson, Direct sum subset decompositions of $Z \ldots \ldots$ 